\title{
Design of Hydraulic Rail Brake System of Mine Inclined Lane Car
}

\author{
Xiang Hengjin \\ Mechanical and Electronic Department, Xuzhou Institute of \\ Technology \\ Xuzhou, China \\ e-mail: sunjian751@163.com
}

\author{
Sun Jian \\ Mechanical and Electronic Department, Xuzhou Institute of \\ Technology \\ Xuzhou, China \\ e-mail: sunbin275@163.com
}

\author{
Xu Kang \\ Mechanical and Electronic Department, Xuzhou Institute of \\ Technology \\ Xuzhou, China \\ e-mail:15895233200@163.com
}

\begin{abstract}
To improve the inclined lane car braking reliability, in this paper, the theoretical analysis of the braking force and the brake parameters of the inclined roadway are carried out, developed a new type of hydraulic track brake device. The device use two levels of the hydraulic cylinder symmetrically installed on both sides of the rail, the force of the track is uniform, and the braking force is large, avoiding the effects of manufacturing and installation errors on the rail brake and improving the inclined lane of vehicle braking stability and reliability.
\end{abstract}

Keywords-Inclined lane car; mine; Over-speed protection; hydraulic braking system

\section{INTRODUCTION}

Slope railway vehicles usually use the steel wire rope traction, in order to adapt to the large gradient transport, but its security problem has been bothering people. Safe and effective braking is the key to the inclined lane rail vehicle safety. Catching trap rail type, cable, plug claw type, hold wheel is the most common form of car braking, but doesn't have a high level of safety reliability. In this paper, the new type inclined lane car braking way, using the hydraulic system to drive the two synchronous clamping cylinder work, hold rail car braking friction plate to achieve people on the device.

\section{BRAKE RESISTANCE CALCULATION}

In the design of braking deceleration is inclined lane car a very key technical indicators, in many references are stated. In the current effective MT388-2007 standard explicitly defines the braking deceleration refers to the average braking deceleration and brake process its estimation computation formula is as follows:

$$
a=\frac{v^{2}}{2 s}
$$

In the type, $a$-The average braking deceleration, $\mathrm{m} / \mathrm{s}^{2} ; \quad \mathrm{V}$-Slope of the braking of vehicle speed, $\mathrm{m} / \mathrm{s}$; $S$-Slope car buffer distance, $\mathrm{m}$.

Inclined lane person car force analysis:

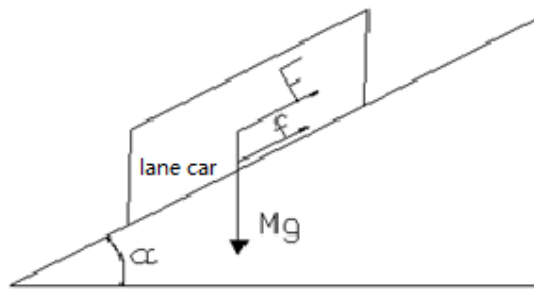

Figure.1. Vehicles force diagram

$$
\begin{gathered}
F+f-M g \sin \alpha=M a \\
f=M g \varpi \sin \alpha
\end{gathered}
$$

In the type, $\mathrm{f}$-One car running resistance, $\mathrm{F}$ - The braking force, $\alpha$-The Angle of mine, a-Brake deceleration, g-The acceleration of gravity.

The technical parameters of slope car people hang see the table below:

TABLE I. TABLE STYLES

\begin{tabular}{|l|c|l|c|}
\hline Parameters & Value & Parameters & Value \\
\hline $\begin{array}{l}\text { Head of vehicle } \\
\text { weight }\end{array}$ & $2200 \mathrm{~kg}$ & $\begin{array}{l}\text { The tail of vehicle } \\
\text { weight }\end{array}$ & $1000 \mathrm{~kg}$ \\
\hline $\begin{array}{l}\text { The number of } \\
\text { load }\end{array}$ & 15 & $\begin{array}{l}\text { Maximum } \\
\text { traction }\end{array}$ & $60 \mathrm{KN}$ \\
\hline $\begin{array}{l}\text { Maximum } \\
\text { speed }\end{array}$ & $4 \mathrm{~m} / \mathrm{s}$ & $\begin{array}{l}\text { Maximum buffer } \\
\text { distance }\end{array}$ & $1.4 \mathrm{~m}$ \\
\hline Air travel time & $0.2 \mathrm{~s}$ & $\begin{array}{l}\text { Damping } \\
\text { coefficient }\end{array}$ & 0.02 \\
\hline
\end{tabular}


When the car is full with maximum braking force as an example calculation:

$$
F=M a+M g \sin \alpha-M g \varpi \sin \alpha
$$

Because of the different Angle oblique lane, the train runs according to the different set of columns. Weight $70 \mathrm{~kg}$ average, passengers 45 people about $3150 \mathrm{~kg}$, section 4 vehicle weight $5400 \mathrm{~kg}$, the total mass $\mathrm{M}=8550 \mathrm{~kg}$; Acceleration of $5.71 \mathrm{~m} / \mathrm{s}$, take $9.8 \mathrm{~N} \mathrm{~g} / \mathrm{kg}, 0.02$, braking force calculation is as follows:

$$
F=48820 N+82114 \times \sin \alpha \quad\left(31^{\circ} \leq \alpha \leq 40^{\circ}\right)
$$

\section{Working PRinCIPLE ANd STRUCTURE DESIGN OF BRAKE}

According to stress analysis and the car run time of car resistance calculation, got the car braking when the maximum braking force required size, determine the appearance of the brake hydraulic cylinder size and the size of the system provides the pressure needed. On the basis of the above analysis, this paper designed a set of new rail brake, the brake hydraulic cylinder horizontal, with two hydraulic cylinders placed on the rails, cylinder run at the same time, both sides have the same size of the braking force, braking stable and reliable. The structure schematic diagram as shown:

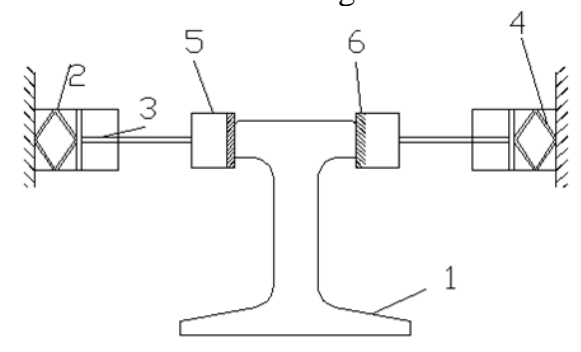

Figure.2. Structure diagram of the rail brake device

1. rail; 2. the hydraulic cylinder; 3 . the piston rod; 4. Disc spring; 5. the brake shoe; 6 . friction plate

Hydraulic cylinder 2 is fixed on a chassis, braking hydraulic oil in the oil chamber to push the piston rod 3 to 3 rail movement, thus brake shoes 5 and the guide rail 1 came into contact with, in order to produce larger brake friction, improve the reliability degree of car braking, on the brake shoe installation friction plate 6 . The friction plate has low cost, good braking performance, easy to install and remove. In the hydraulic cylinder with a disc spring 4, in which the butterfly spring with a reset function, is an essential part of the brake system. When vehicles need to restart, then the butterfly spring accumulation of elastic potential energy, so that the piston cylinder returned to the original position, brake shoes, more than 5 friction 6 automatic and rail separation, people and vehicles which is able to start. This brake on both sides of the device, so that the car is not due to the brake when the brake is different from the left and right. The level of the hydraulic cylinder is placed, so the rail can only be subjected to the horizontal direction, which can reduce the working pressure of the hydraulic cylinder.

\section{DESIGN OF HydRAULIC LOCK RAIL BRAKE SYSTEM}

\section{A. The main function of the hydraulic system}

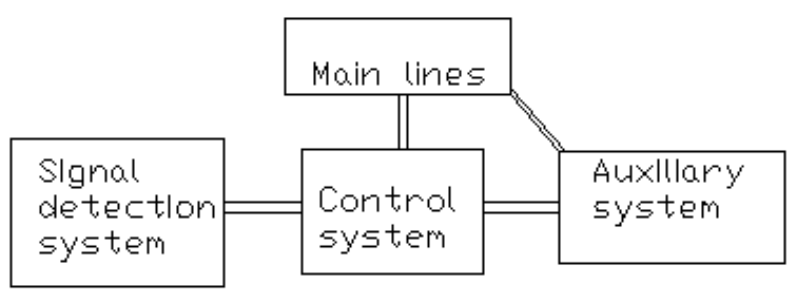

Figure.3. Schematic Diagram of System Structure

As shown in the picture, the system is mainly composed of four parts, which are the signal monitoring system, the control component, the brake main circuit and the auxiliary system. The detection system detects the signal and passes it to the control device, which enables it to turn on or off the switch, thus controlling the working state of the main circuit, the auxiliary system and the main circuit, thus improving the stability of the system.

\section{B. System Working Principle}

Figure 4 is a hydraulic system for the rail brake system, including signal detection and control system, control components, and the composition of the auxiliary system.

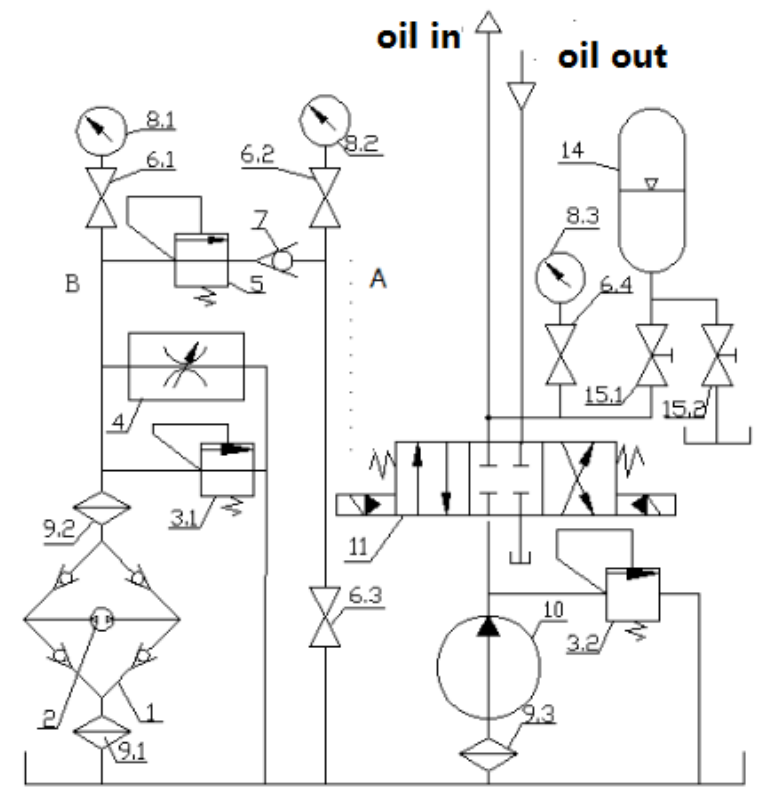

Figure.4.Principle diagram of the brake system

1. hydraulic bridge; 2 . The bidirectional quantitative pump; 3.1. overflow valve; 3.2. counterbalance valve; 4 . flow control valve ; 5 . sequence valve; 6.1,6.2,6.3,6.4. ball valve; 7. one-way valve; 8.1,8.2. liquid piezometer; 9.1,9.2,9.3. oil filter; 10. oil hydraulic pump; 11. three-position four-way directional control valve; 13 . hydraulic cylinder; 14. energy accumulator; 15.1,15.2. brake valve; 


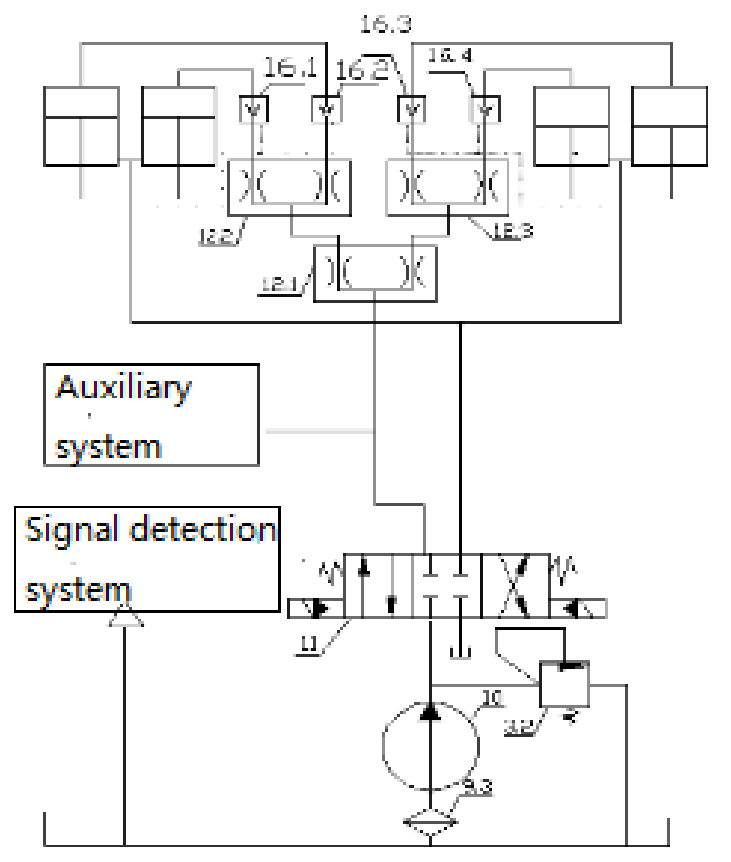

Figure.5. Test system and auxiliary system parts

12.1,12.2,12.3. flow distributing and collecting valve 16.1,16.2,16.3,16.4. hydraulic control one-way valve

In order to guarantee in a two-way operation, the system can normal use, quantitative pump and hydraulic pressure system uses two-way bridge. In the hold rail hydraulic braking system, two-way quantitative pump 2 by installed in the car wheel driven directly take speed. And the quantity of hydraulic pump oil discharge is directly proportional to the speed of the car, past the flow control valve 4 flow rate proportional to the speed of the car. Pipeline flow depends on the flow control valve 4 setting, locomotive running, adjusted by the flow control valve 4 , to ensure that the locomotive when speeding, point B pressure valve 5 can just reached the open order. Such as pipeline flow less than the setting value of flow control valve 4, there is no pressure in the pipeline; Such as greater than the setting value, the pressure increases rapidly in pipeline, the pressure applied to the hydraulic oil release system, the hydraulic oil driving hydraulic cylinder brake work.

\section{System Implementation Process}

Executive system for rail brake, receive signal detection control system, the control of executive system and signal detection control system connected by A pipeline.

\section{(1) signal detection system}

Signal detection control system including 2 1, two-way hydraulic bridge quantitative pump, relief valve, flow control valve, ball valve, pressure gauge, $6.14,3.1,8.1$, the sequence valve $6.3,5,7$ check valve, ball valve, ball valve, pressure gauge and oil filter 9.1, 9.2, 8.2, 6.2. Hydraulic pump for twoway pump, hydraulic bridge 1 by four one-way valve of 1.1 ,
1.2, 1.3, 1.2, its role is to enable two-way hydraulic pump hydraulic oil no matter really inversion can output. When the flow control valve 4 after setting, such as hydraulic pump output flow rate is less than 4 setting flow control valve flow, the hydraulic table 8.1 reading is 0 , pipeline oil flows back to the fuel tank through flow control valve 4; Such as hydraulic pump output flow rate is greater than the flow control valve 4 the setting value, the flow control valve 4 set out flow, a sharp rise in the oil pressure at this time, sequence valve 5 open, and then three four-way reversing valve control hydraulic control type 11 , the brake.

\section{(2) Control system}

Perform system consists of hydraulic pump 10, back pressure valve of 3.2 and three four-way reversing valve 11 . When people speeding, a sharp rise in the oil pressure sequence valve 5 open, hydraulic drive electro-hydraulic directional control valve type 11 to the left, from the pressure of hydraulic pump 10 oil by reversing valve left, into the hydraulic cylinder inlet chamber, piston rod, drive to rail brake, friction in contact with the track, implementation of vehicle brake. Speed wheel brake success after stop driving, sequence valve 5 closed, 11 back to the median reversing valve, reversing valve $\mathrm{A}$ and $\mathrm{B}$ oil mouth closed, and the hydraulic cylinder lock. Due to the leak valve, hydraulic cylinder lock accuracy is not high, the accumulator to oil compensating and pressure maintaining guarantee the stability of hydraulic cylinder pressure, brake to keep good work condition. Exit the braking state, electro-hydraulic directional control valve in power, right, brake hydraulic oil through the right place, right after a one-way speed regulating valve in hydraulic cylinder cavity, the piston rod back, holding the rail device to loosen.

\section{(3) the secondary system}

Auxiliary components are mainly oil filter 14, 9.1, 9.2, 9.3, accumulator tank and the tubing, etc. Accumulator vehicle before debugging, accumulator for energy storage. Accumulator pressure is $3.5 \sim 30 \mathrm{mpa}$, the range of $0.6 \sim 200$ l capacity, temperature range is $-10 \sim+65^{\circ} \mathrm{C}$. Accumulator working volume selected by the brake pressure, the working process of the accumulator observe Boyle's law, that is:

$$
\mathrm{p}_{0} \mathrm{~V}_{0}^{\mathrm{n}}=\mathrm{p}_{\max } \mathrm{V}_{\min }^{\mathrm{n}}=\mathrm{pV}^{\mathrm{n}}=C
$$

This formula is derived:

$$
\mathrm{V}-\mathrm{V}_{\min }=V_{0} P_{0}^{\frac{1}{n}}\left[\left(\frac{1}{P}\right)^{\frac{1}{\mathrm{n}}}-\left(\frac{1}{\mathrm{P}_{\max }}()^{\frac{1}{\mathrm{n}}}\right]\right.
$$

$$
\text { So get: } \quad V_{0}=\frac{V-V_{\min }}{P_{0}^{\frac{1}{n}}\left[\left(\frac{1}{P}\right)^{\frac{1}{n}}-\left(\frac{1}{P_{\max }}\right)^{\frac{1}{n}}\right]}
$$

In the type, $\left(\mathrm{V}-\mathrm{V}_{\max }\right)$ Is an effective working capacity of accumulator make it equal $\Delta \mathrm{V}$, for isotherm process, total volume: 


$$
\begin{gathered}
\mathrm{V}_{0}=\frac{\mathrm{p}}{\mathrm{p}_{0}} * \frac{\mathrm{p}_{\max }}{\mathrm{p}_{\max -\mathrm{p}}} \Delta \mathrm{V} \\
\mathrm{V}_{0}=\frac{\Delta \mathrm{V}}{\mathrm{p}_{0}^{\frac{1}{1.4}}\left[\left(\frac{1}{p}\right)^{\frac{1}{1.4}}-\left(\frac{1}{p_{\max }}\right)^{\frac{1}{1.4}}\right]}
\end{gathered}
$$

is:

For the adiabatic process, when $n=1.4$, the total volume

Using the formula(8), (9) to calculate the accumulator volume, Need to determine the value of $\mathrm{P}_{0}, \mathrm{p} 、 \mathrm{p}_{\max }$ and $\Delta \mathrm{V}$.

(4) the brake system

Brake system by shunt collector valve $12.1,12.2,12.3$, hydraulic control one-way valve 16.1, 16.2, 16.3, 16.4, and four hydraulic cylinder. Of four hydraulic cylinder two brake (FIG. 2. Brake work chart), brake force for the track. Shunt collector of two hydraulic cylinder valve control flow into or out of traffic, can make the two hydraulic cylinder under different load can still achieve synchronization. Hydraulic controlled check valve in the system is to prevent the two cylinder piston stops under the different load and through the throttle orifice in oil.

\section{CONCLUSION}

In this paper, a new hydraulic brake, and a reliable hydraulic braking system, the use of synchronous hydraulic cylinder to achieve smooth braking, good braking performance. Compared with the conventional car brake, change new car brakes, brake short journeys, braking force is larger and symmetrical on both sides along the rail. System with high precision hydraulic valve in the speed of the car signal detection, amplification and select and, in turn, drives the brake, to complete the driver braking, harvester system can on-line detection speed, more stable and reliable, and easy to debug maintenance, in addition, the system has the automatic braking and artificial braking two braking way, to face the emergency situation. This system provides a solution to overspeed protection and rope protection theory and method, can be applied to the coal mine or coal mine outside of all kinds of railway equipment, has extensive application prospect.

\section{References}

[1] Dai Zhiye. Light trackless auxiliary truck brake structure design [J]. Journal of coal mine machinery. 2007.28. (3) : 1-3.

[2] Zhang Linhui. Explosion-proof rubber-tyred vehicle hydraulic brake system design [J]. Journal of coal mine machinery. 2012.33 (11) : 1-3.

[3] Jiang Shiwen Jiang Hanwu, Li Jinxi. Automatic vehicle hydraulic brake system: China, 200810243979 X [P]. 2008-10-24.

[4] Zhang yuanyue. Hydraulic and hydraulic transmission [M] Chengdu: southwest jiaotong university press, 2014:149154.

[5] Liu Yanping. Several hydraulic synchronous circuit analyses [J]. Journal of non-ferrous metals processing. 2004 (6) : 36-37.

[6] Sun Huan, Chen editor for the mold mechanical principles [M]. Beijing: Higher Education Press, 2000

[7] Sun Zhili, cold-hing gather, Wei Yangang mechanical design editor Shenyang: Northeastern University Press, 2000.

[8] Su dong-hai, Han Guohui, etc. Hydraulic synchronous control system and its application [J]. Journal of shenyang university of technology. 2005, 27 (4) : 364-367. 